\title{
Acyanotic Truncus Arteriosus Type 4 in a Sudden Infant Death: A Case Report
}

\author{
Nadiawati Abdul Razak, Lee Jiun Yih and Khairul Anuar Zainun
}

\section{ABSTRACT}

\begin{abstract}
A congenital cyanotic heart defect such as Truncus Arteriosus (TA) is rare and is represented by a single arterial trunk that develops from the heart and gives rise to the pulmonary trunk in several manners. TA comprises $0.7 \%$ of all complex congenital heart malformations caused by numerous aetiologies, with the majority being genetic in origin. This malformation can be recognised in the prenatal period so that further medical intervention can be advocated. There are four types of the defect based on the CollettEdwards classification. Type 4 is a rare form in which the pulmonary arteries are non-existent. Therefore, the lungs are supplied by major aortopulmonary collateral arteries. It may also describe this anatomical picture as pulmonary atresia with VSD. We report here a unique case of truncus arteriosus type 4 in an apparently well-thriving and acyanotic 6month-old male infant. The deceased was presented with a brief history of inconsolable cry shortly before his demise and the underlying cardiac abnormalities were discovered at autopsy. A meticulous post-mortem examination elucidates a better diagnosis approach. Genetic counselling can be offered to parents in recurrent cases, such as cases of consanguinity.
\end{abstract}

Keywords: Cyanotic heart disease, forensic, paediatric death, post-mortem examination, truncus arteriosus.
Submitted : September 1, 2021

Published : October 7, 2021

ISSN: $2593-8339$

DOI: $10.24018 /$ ejmed.2021.3.5.1036

\section{N. A. Razak*}

Forensic Unit, Faculty of Medicine and Defence Health, National Defence University of Malaysia, Malaysia. (e-mail: nadiawati@upnm.edu.my)

J. Y. Lee

Department of Forensic Medicine, Hospital Serdang, Ministry of Health, Malaysia, Malaysia.

(e-mail: alexandra147@gmail.com)

K. A. Zainun

Department of Forensic Medicine, Hospital Serdang, Ministry of Health, Malaysia, Malaysia.

(e-mail: drkhairulz@moh.gov.my)

*Corresponding Author

\section{INTRODUCTION}

Truncus arteriosus (TA) is an uncommon congenital heart defect caused by the failure of a single arterial vessel to split during embryologic development. It is extremely rare, accounting for only 0.7 percent of all congenital cardiac lesions [1]. The name "truncus arteriosus" refers to a single arterial vessel that originates from both the left and right ventricles via a single semilunar truncal valve, giving rise to the systemic, pulmonary, and coronary vascular circulations without an aortic or pulmonary vessel [2]. The tricuspid truncal valve is seen in the majority of cases $(70 \%)$ followed by quadricuspid $(21 \%)$ and bicuspid $(9 \%)$, with more than four truncal leaflets being observed on rare occasions.

Patients with common truncal abnormalities almost always have a large, nonrestrictive subarterial ventricular septal defect (VSD) below the truncal valve. Valvular regurgitation, stenosis, or both may result from this disorder. The origins of the pulmonary arteries are used to classify TA patients [3], [4]. Collett Edwards (C\&E) and Van Praagh created two systems. Collett and Edwards' taxonomy is commonly used and describes four forms of TA. Table I shows a summary of both classifications.
TABLE I: SUMMARY OF THE CLASSIFICATION OF THE TRUNCUS ARTERIOSUS

Collett and Edwards classification

\begin{tabular}{cl}
\hline \hline & \multicolumn{1}{c}{ Collett and Edwards classification } \\
\hline \hline Type 1 & $\begin{array}{l}\text { a single pulmonary artery trunk that branches out from the } \\
\text { common truncus to form the right and left pulmonary arteries } \\
\text { the main pulmonary arterial trunk is absent and the right and } \\
\text { left pulmonary arteries originate together } \\
\text { the right and left pulmonary arteries branched separately from } \\
\text { the truncus and pulmonary truncus is not developed } \\
\text { the pulmonary arteries are absent, and the lungs are supplied by } \\
\text { major aorto-pulmonary collateral arteries since. This condition } \\
\text { is also known as pulmonary atresiwith VSD }\end{array}$ \\
Type 4 & \multicolumn{1}{c}{ Van Praagh system } \\
\hline \hline Type A1 & $\begin{array}{l}\text { similar as Collet and Edwards TA Type 1 } \\
\text { similar as Collet and Edwards TA Type 2 } \\
\text { the right pulmonary artery branch (typically) arises from the } \\
\text { common trunk, whilst the other lung is supplied by the } \\
\text { pulmonary artery originating from the aortic arch itself, or by a } \\
\text { vessel originating from the ductus arteriosus or the major } \\
\text { aortopulmonary collaterals. } \\
\text { it is associated with an interrupted aortic arch or aortic } \\
\text { coarctation in addition to type 1 and 2 C\&E TA defect. }\end{array}$ \\
Type A3
\end{tabular}

The Van Praagh system type A4 accounts for $14 \%$ of cases and has a more complicated pathophysiology. The presence of a patent foramen ovale and atrial septal defect is common in this type. However, aortic coarctation, abnormal pulmonary venous outflow, hypoplasia of the left lung, anomalous origin of the subclavian artery, single ventricle, lack of connection between the right arteries and veins, hypoplastic right ventricle, tubular hypoplasia of the aortic arch, and double aortic anomaly are rare [5]. We present the 
case of a 6-month-old male infant who had no cyanosis or symptoms and signs of heart failure, and whose mother failed to make an early referral to a cardiologist despite the presence of a cardiac murmur after birth. The final diagnosis of a truncus arteriosus type 4 was discovered at post-mortem examination.

\section{CASE REPORT}

This is a 6-months-old non-native male infant who was brought in dead to the mortuary by the police. The police have ordered a post-mortem examination to determine the cause of death. A medical history was taken by both the mother and the police simultaneously to rule out any non-accidental injuries. According to the mother, the baby was her first male child in the family after waiting many years. Her last delivery was ten years ago. Despite her age-related pregnancy risk and financial constraints, she had not sought adequate antenatal care. The baby was born in a private health center and a cardiac murmur was detected after birth. Early referral to a pediatric cardiologist was arranged on $18^{\text {th }}$ day of life but she failed to do so. She also claimed that the baby was thriving well, feeding well, and showed no signs of cyanotic heart disease. At the hospital, the baby collapsed after a brief episode of inconsolable crying. He was resuscitated but succumbed to death. A skeletal survey was performed before autopsy. Postmortem chest X-ray showed a "boot-shaped" heart with increased pulmonary markings. Otherwise, no fractures of the long bones or other deformities were noted.

At autopsy, the body was that of a normally built male infant weighed $6.31 \mathrm{~kg}$. The growth parameters ranged from 50 to $75^{\text {th }}$ centile. No facial dysmorphisms were appreciated. The face and fingernail beds were not cyanotic and there was no clubbing of fingers. The post-mortem changes were consistent with the time of death. There was no external bodily injury, but the chest cage appeared asymmetrical.

Internal examination revealed pathological changes in the heart and lungs. The right pleural cavity contained $20 \mathrm{ml}$ of straw-colored pleural effusion while the left pleural cavity was clear. Both lungs were congested and edematous and weighed 36 grams and 24 grams, respectively. The trachea was clear, and the thymus showed no petechial hemorrhage. The pericardium was intact and clear. The heart weighed 80 grams complicated with pulmonary artery atresia, atrial septal defect (ASD) with patent foramen ovale (PFO) and membranous ventricular septal defect (VSD) just below the pulmonary valve (Fig. 1A and $1 \mathrm{~B}$ ). The wall of the right ventricle was thickened $(13 \mathrm{~mm})$, the wall of the left ventricle was $6 \mathrm{~mm}$, and the thickness of the interventricular septum was $10 \mathrm{~mm}$. The diameter of the right and left ventricles were $16 \mathrm{~mm}$ and $20 \mathrm{~mm}$, respectively. The blood from the right ventricle flowed directly into the root of the aorta. The aortic arch has normal branches namely the right brachiocephalic trunk, left common carotid artery and left subclavian artery.

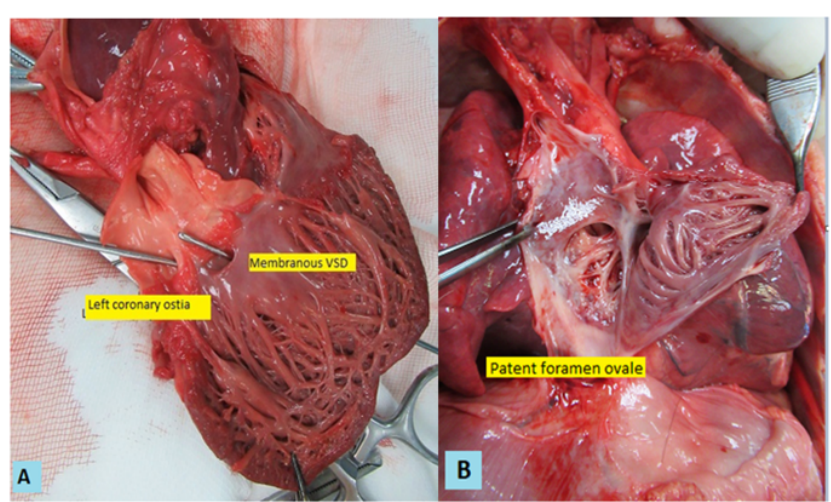

Fig. 1. (A) Left ventricle was opened and showing left coronary ostia and membranous VSD. (B) Right atrium was opened and showing patent foramen ovale.

The right and left aortopulmonary collateral arteries arise from the descending aorta $3 \mathrm{~mm}$ from the left subclavian artery (Fig. 2). The aortic valve had a tricuspid sinus vasalva and the left coronary artery arose from the left coronary cusp whereas the right coronary ostia was absent. The intima of the aorta was healthy and no coarctation was seen.

Apart from the above findings, the other internal organs showed no abnormalities. Histological examination of the lungs showed features of pulmonary hypertension and pulmonary hemorrhage. In view of the postmortem findings, the cause of death in this case was established as complex congenital heart disease.

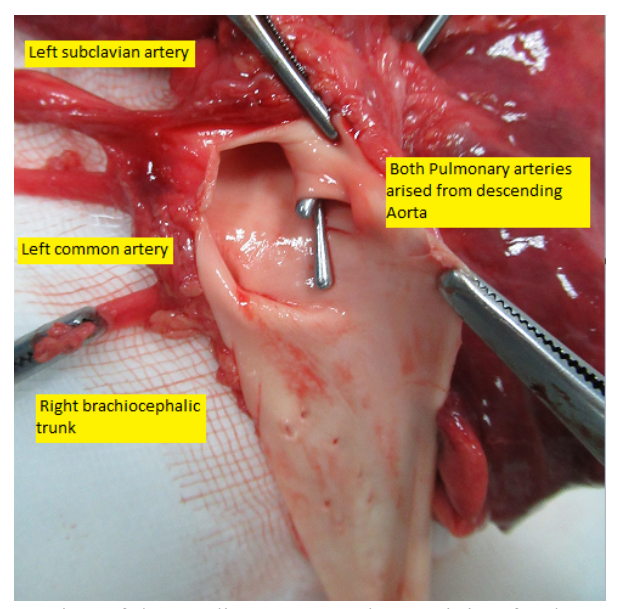

Fig. 2. Opening of descending aorta to show origin of pulmonary artery.

\section{DISCUSSION}

Truncus arteriosus (TA) is referred to the common arterial trunk and the common aorticopulmonary trunk. The etiology of truncus arteriosus is mostly genetic; other causes include maternal alcohol exposure during the first trimester, maternal gestational diabetes mellitus, and exposure to teratogens such as retinoic acid and bisdiamine. A microdeletion of $22 \mathrm{q} 11.2$ is the genetic aetiology, which occurs in $30-40 \%$ of cases [1]. There is no significant predilection with respect to gender, although a series of report point towards male predominance. Extra-cardiac anomalies found sporadically in patients with TA include abnormalities of the renal, vertebral, ribs and alimentary tract, associated with the microdeletion of chromosome $22 \mathrm{q} 11.2$ which is hypothesized to affect the migration or development of the cells of the cardiac neural 
crest accounts in $30-35 \%$ patients with TA. This is called the $\mathrm{CATCH} 22$ syndrome a combination of Di George, velocardiofacial and conotruncal anomaly faces syndromes [3].

Tachypnea, poor feeding, failure to thrive and sign of heart failure are common symptoms of truncus arteriosus in the first few weeks of life. The patients seldom reach their first birthday [5]. In our case, the deceased survived to 6-months of age despite having a type 4 TA according to Collett and Edwards classification (pseudo-truncus) [3]. The pulmonary arteries were absent, and the pulmonary circulation was supplied by aorto-pulmonary collateral arteries from the descending aorta.

Cyanosis and systemic ventricular volume overflow are frequent symptoms of TA. The common arterial trunk receives blood from both ventricles. The magnitude of pulmonary blood flow is determined by the ratio of resistance to flow in the pulmonary and systemic vascular beds, which is acquired from this combined ventricular outflow. During systole, the output of the left and right ventricles combines (albeit not fully) at the level of the common arterial trunk, resulting in subnormal systemic arterial oxygen saturation. Because the systemic and pulmonary circulations are practically parallel during systole, pulmonary blood flow is often at least three times greater than systemic blood flow, resulting in pulmonary over circulation and increased myocardial work.

As a result, resting oxygen demand increases and metabolic reserve diminished [4]. Therefore, patients in early infancy usually present with; cyanosis, diaphoresis, tachypnea, tachycardia, signs of congestive heart failure and failure to thrive. Cyanosis may not be visible in extremely young infants with increased pulmonary vascular resistance. Even in slightly older newborns and young babies, pulmonary over circulation and left and right ventricular draining into the aorta and pulmonary arteries, respectively, frequently result in systemic oxyhemoglobin saturation considerably above $90 \%$, as in our case [6].

At presentation, a chest X-ray is the main key finding. Cardiomegaly and increased pulmonary markings / engorgement (the pulmonary vessels receive blood at systemic pressure) are typical [7]. In patients with a right aortic arch, these radiographic findings in conjunction with increased pulmonary vascular markings suggest a truncus arteriosus [4], [7]. In cases with an absent pulmonary artery, the pulmonary vascular pattern on this side is diminished [3]. Other radiological modalities, including echocardiography with cross-sectional and Doppler flow studies, and magnetic resonance imaging (MRI), are sufficient to confirm the diagnosis and fully characterize the various anatomical features in most patients TA.

The prognosis of TA is poor without surgical intervention, which is the mainstay of treatment and involves the creation of a new pulmonary artery using tissue from another source [7], [8]. This is essential to avoid pulmonary vascular disease, which would occur if the patient was not corrected.

Our case illustrates the rare case of a type 4 TA according Collett and Edwards classification (pseudo-truncus), which presented with acyanotic features and good growth. It is important to conduct a meticulous autopsy to demonstrate the complexity of the pulmonary vascular disease and excluding any microbiology infection and trauma. This would help to determine the correct diagnosis and manner of death. The forensic pathologist must play a role in counselling the mother, emphasizing early intervention and genetic counselling to prevent reoccurrence in the subsequent pregnancy.

\section{CONCLUSION}

Truncus arteriosus is a rare pathology diagnosed during postmortem examination and has numerous etiologies, many of which are genetic in origin. This case is unique in that it presents as acyanotic and well-thriving infant and is the first case reported in Malaysia to the best of authors knowledge.

\section{CONFLICT OF INTEREST}

The authors declare that there is no conflict of interests regarding the publication of this paper.

\section{ACKNOWLEDGMENT}

The authors thank the Director General of Health Malaysia for permission to publish this paper. F.A. thanks National Defence of University Malaysia for financial support.

\section{REFERENCES}

[1] A. Cifareli and L. Ballerini, "Truncus Arteriosus," Pediatric cardiology 24: 569-73, 2003.

[2] P. Volpe, D. Paladini, M. Marasini, A. L. Buonadonna, M. G. Russo, G. Caruso and M. Gentile, "Common arterial trunk in the fetus: characteristics, associations, and outcome in a multicentre series of 23 cases," Heart, 89(12), 1437-1441, 2003.

[3] D. Verhaert, J. Arruda, P. Thavendiranathan, C. S. Cook and V. S. Raman, "Truncus arteriosus with aortic arch interruption:cardiovascular magnetic resonance findings in the unrepaired adult," Journal of Cardiovascular Magnetic Resonance 12:16, 2010.

[4] B. Doff and M. D. McElhinney, 2012, "Truncus Arteriosus pathophysiology\&management," Medscape. http://emedicine.medscape.com/article/892489-overview.

[5] J. M. Williams, M. de Leeuw, M. D. Black, R. M. Freedom, W. G. Williams and B. W. Mc Crindle, "Factors associated with outcomes of persistent truncus arteriosus," J Am Coll Cardiol 34:545-53, 1999.

[6] E. Braunwald, P. D. Zipes and P. Libby Heart Disease 6th Ed. WB Saunders, 1536-7, 2001.

[7] H. A. Rajasinghe, D. B. McElhinney, V. M. Reddy, B. N. Mora and F. L. Hanley, "Long-term follow-up of truncus arteriosus repaired in infancy: a twenty-year experience," $J$ Thorac Cardiovasc Surg 113:869-878, 1997.

[8] J. F. N. Taylor, E. Moller, H. James and J. Hoffman, "Persistent truncus arteriosus," Pediatric Cardiovascular Medicine Philadelphia: Churchill Livingstone 499-510, 2000. 